\title{
A Theoretical Analysis of the Reaction Between Ethyl and Molecular Oxygen
}

by

\section{RECEIVED}

James A. Miller, Combustion Research Facility,

FFR 232000

Sandia National Laboratories, Livermore, CA 94551-0969, U.S.A.

Stephen J. Klippenstein, Department of Chemistry

Case Western Reserve University, Cleveland, Ohio 44106-7078, U.S.A. and

Struan H. Robertson, Molecular Simulations Inc.

Cambridge, CB5 8RE, U.K.

Corresponding Author:

James A. Miller

MS 9055

Sandia National Laboratories

Livermore, CA 94551-0969

Phone: (925) 294-2759

Fax:

(925) 294-2276

E-Mail: jamille@ca.sandia.gov

Presentation Mode: Oral

Preferred Publication: Proceedings

Category:

Reaction Kinetics of Combustion

Word Count:

10 pages (text + references @ 400 words/page) $\quad 4000$

1 table @ 200 words

7 figures@200words/figure 


\section{DISCLAIMER}

This report was prepared as an account of work sponsored by an agency of the United States Government. Neither the United States Government nor any agency thereof, nor any of their employees, make any warranty, express or implied, or assumes any legal liability or responsibility for the accuracy, completeness, or usefulness of any information, apparatus, product, or process disclosed, or represents that its use would not infringe privately owned rights. Reference herein to any specific commercial product, process, or service by trade name, trademark, manufacturer, or otherwise does not necessarily constitute or imply its endorsement, recommendation, or favoring by the United States Government or any agency thereof. The views and opinions of authors expressed herein do not necessarily state or reflect those of the United States Government or any agency thereof. 


\section{DISCLAIMER}

Portions of this document may be illegible in electronic image products. Images are produced from the best available original document. 


\title{
A Theoretical Analysis of the Reaction Between Ethyl and Molecular Oxygen
}

\author{
James A. Miller \\ Combustion Research Facility \\ Sandia National Laboratories \\ Livermore, CA 94551-0969, U.S.A. \\ Stephen J. Klippenstein \\ Department of Chemistry \\ Case Western Reserve University \\ Cleveland, Ohio 44106-7078, U.S.A. \\ and \\ Struan H. Robertson \\ Molecular Simulations Inc. \\ Cambridge, CB5 8RE, U.K.
}

\begin{abstract}
Using a combination of electronic-structure theory, variational transition-state theory, and solutions to the time-dependent master equation, we have studied the kinetics of the title reaction theoretically over wide ranges of temperature and pressure. The agreement between theory and experiment is quite good. By comparing the theoretical and experimental results describing the kinetic behavior, we have been able to deduce a value for the $\mathrm{C}_{2} \mathrm{H}_{5}-\mathrm{O}_{2}$ bond energy of $\sim 34 \mathrm{kcal} / \mathrm{mole}$ and a value for the exit-channel transition-state energy of $-4.3 \mathrm{kcal} / \mathrm{mole}$ (measured from reactants). These numbers compare favorably with our electronic-structure theory predictions of $33.9 \mathrm{kcal} / \mathrm{mole}$ and -3.0 $\mathrm{kcal} / \mathrm{mole}$, respectively. The master-equation solutions show three distinct temperature regimes for the reaction, discussed extensively in the paper. Above $\mathrm{T} \approx 700 \mathrm{~K}$, the reaction can be written as an elementary step, $\mathrm{C}_{2} \mathrm{H}_{5}+\mathrm{O}_{2} \leftrightarrow \mathrm{C}_{2} \mathrm{H}_{4}+\mathrm{HO}_{2}$, with the rate coefficient,

$$
\mathrm{k}(\mathrm{T})=3.19 \times 10^{-17} \mathrm{~T}^{1.02} \exp (2035 / \mathrm{RT}) \mathrm{cm}^{3} / \text { molec.-sec., }
$$

independent of pressure even though the intermediate collision complex may suffer a large number of collisions.
\end{abstract}




\section{INTRODUCTION}

The reactions of alkyl radicals with molecular oxygen constitute an important class of reactions in combustion. It is the properties of these reactions that cause the change in oxidation mechanism of alkanes between $500 \mathrm{~K}$ and $800 \mathrm{~K}$ and the "negative temperature coefficient" of their overall oxidation rate in the same temperature regime [1-3]. Ethyl $\left(\mathrm{C}_{2} \mathrm{H}_{5}\right)$ is the prototype alkyl radical, and consequently its reaction with $\mathrm{O}_{2}$ has been studied extensively in the laboratory [4-12]. There have also been several attempts to treat the reaction theoretically $[8,13,14]$, the most extensive of which is the study of Wagner, et al [8]. The latter authors also provide a comprehensive review of the literature through 1990 , so we may dispense with that here.

The present investigation is theoretical. It is a rather substantial extension of the work of Wagner, et al., who treated the $\mathrm{C}_{2} \mathrm{H}_{5}+\mathrm{O}_{2}$ reaction as the sum of four separate elementary reactions, each with its own pressure- and temperature-dependent rate coefficients. These rate coefficients were calculated from chemically activated RRKM theory using canonical variational transition-state theory for the loose transition state and a pseudo strong-collider model to calculate the effects of collisions. In the present investigation, we use $a b$ initio electronic structure theory (density functional theory (DFT) and a G2-like method) to characterize various features of the potential energy surface, and we use microcanonical $(\mu \mathrm{VT})$ and microcanonical/J-conservative ( $\mu \mathrm{VT}-\mathrm{J})$ variational transition-state (RRKM) theory to calculate the high pressure limit of the addition reaction and the zero-pressure limit of the bimolecular channel. Most importantly, however, we use solutions to the time-dependent master equation to characterize the reaction over wide ranges of temperature and pressure, including the "transition region" between $500 \mathrm{~K}$ and $800 \mathrm{~K}$.

\section{THEORY}

Figure 1 shows a potential energy diagram for the $\mathrm{C}_{2} \mathrm{H}_{5}+\mathrm{O}_{2}$ reaction. The energies of the stationary points on the potential energy surface (PES) come from the work described below. Our objective is to calculate the total rate coefficient for the reaction, $\mathrm{k}(\mathrm{T}, \mathrm{p})$, and the branching fraction $\alpha(T, p)$, i.e. the fraction that forms the bimolecular products $\mathrm{C}_{2} \mathrm{H}_{4}+\mathrm{HO}_{2}$.

\section{QUANTUM CHEMISTRY}

The $\mathrm{C}_{2} \mathrm{H}_{5}+\mathrm{O}_{2}$ reaction has been the subject of a number of $a b$ initio quantum chemical studies (cf. [15-17]. and references cited therein) with methods ranging from density functional theory to more traditional $\mathrm{MP}_{\mathrm{n}}$, coupled cluster, and configuration interaction methods. The vibrational frequencies obtained in the B3LYP [18] /DZP analysis of [16] are employed in the present investigation. In the 
interest of further delineating the allowable energetics, we have evaluated stationary-point energies with an approach that is closely analogous to the G2 method [19]:

$$
\begin{aligned}
& \mathrm{E}[\mathrm{QCISD}(\mathrm{T}) / 6-311++\mathrm{G}(3 \mathrm{df}, 2 \mathrm{pd})] \cong \mathrm{E}[\mathrm{QCISD}(\mathrm{T}) / 6-311++\mathrm{G}(\mathrm{d}, \mathrm{p})]+ \\
& \mathrm{E}[\mathrm{MP} 2 / 6-311++\mathrm{G}(3 \mathrm{df}, 2 \mathrm{pd})]-\mathrm{E}[\mathrm{MP} 2 / 6-311++\mathrm{G}(\mathrm{d}, \mathrm{p})]+\mathrm{HLC}+\mathrm{E}^{(0)},
\end{aligned}
$$

where $\mathrm{E}^{(0)}$ is the zero-point vibrational energy.

These evaluations and the rate coefficient calculations discussed below employ molecular structures obtained from B3LYP/6-311 ++G(d,p) optimizations. The higher level corrections (HLC) used in different variants of G2 theory [19-21] yield a decrease in the energy (relative to reactants) of about $2.6-3.1 \mathrm{kcal} / \mathrm{mole}$ for each of the stationary points of interest here. In contrast, the more recent G3 theory [27] suggests the HLC should be only $-0.3 \mathrm{kcal} / \mathrm{mole}$, and that this is likely to be a better correction even for calculations at the G2 level. Thus, this smaller correction is employed here.

The results of these G2-like calculations are provided in Table I, and are seen to be in reasonable agreement with the corresponding B3LYP calculations of [16], but they do indicate a general lowering of the energies. Also shown in Table I are the stationary-point energies deduced by comparing our ratecoefficient calculations with experiment. These energies are in good agreement with the ab initio results.

\section{THE LOOSE TRANSITION STATE}

There are no electronic structure calculations from which to draw information about the PES along the $\mathrm{C}_{2} \mathrm{H}_{5}+\mathrm{O}_{2}$ entrance channel, and it is beyond the scope of the present work to provide such information. Consequently, we approximate the potential in this region of the surface by the method described by Miller and Klippenstein [22]. Briefly, the potential consists of three parts:

1) The potential along the reaction coordinate - This part of the potential is approximated by the Varshni function $[22,23]$. The two parameters in the Varshni potential come from knowledge of the bond energy and from a DFT calculation of the force constant matrix at the potential minimum.

2. The potential for the "conserved" degrees of freedom orthogonal to the reaction coordinate This part of the potential corresponds to the degrees of freedom that can be identified as normal-mode vibrations in the separated fragments and is assumed to be the same as in the fragments.

3. The potential for the "transitional" degrees of freedom orthogonal to the reaction coordinate This part of the potential is described in terms of a set of internal angles. The potential is written essentially as a sum of products (in pairs) of sinusoidal functions with the appropriate phases and periods determined by symmetry (see eq. 4 of ref. 22). The coefficients in the expression are functions of the bond distance $\mathrm{R}$ and are determined by calculating the appropriate force constant matrix using 
DFT at the potential minimum, $F_{i j}\left(R_{o}\right)$, and assuming that these matrix elements decay exponentially with bond distance,

$$
F_{i j}(R)=F_{i j}\left(R_{0}\right) \exp \left[-\eta\left(R-R_{0}\right)\right] .
$$

The only adjustable constant is $\eta$, and we adjust its value, $\eta=1.45 \AA^{-1}$, to give an accurate representation of the high-pressure (p), low-temperature (T) rate coefficients.

The sum-of-states functions $\mathrm{N}_{1}^{ \pm}(\mathrm{E}, \mathrm{J})$ and $\mathrm{N}_{1}^{ \pm}(\mathrm{E})$ are calculated with the VARIFLEX [24] computer code using methods developed by Klippenstein [25]. In the former case there is one transition-state dividing surface TS-1 for every E, J combination, and in the latter there is one for every $\mathrm{E}$, where $\mathrm{E}$ is the total energy and $\mathrm{J}$ is the total angular momentum quantum number.

\section{HINDERED ROTORS, SYMMETRY NUMBERS, AND STATE COUNTING}

The $\mathrm{CH}_{3} \ldots \mathrm{CH}_{2}$ torsional mode in the ethyl radical is treated in the present investigation as a hindered rotor using a Pitzer-Gwinn approximation [26] for the canonical partition function of the reactants. The corresponding contribution to the transition state partition function has been evaluated with a microcanonical analog. In particular, the hindered-rotor density of states is evaluated as the classical hindered rotor density times the quantum harmonic density divided by the classical harmonic density. The hindered-rotor rotational constant $\left(15.2 \mathrm{~cm}^{-1}\right)$ is evaluated according to the prescription provided by Pitzer in Eq. (1) of [28]. A sinusoidally hindered potential of period $2 \pi / 3$ is employed with the barrier height set to yield the $a b$ initio harmonic vibrational frequency at the minimum of the hindering potential. Rotational symmetry numbers of 3 and 2 are employed for the ethyl and oxygen fragments, respectively. The transition state evaluations for the entrance channel include the contribution from the binding of only one of the two oxygens. Thus, the net symmetry number for the entrance channel transition state is reduced from 6 to 3. The reaction is assumed to occur only on the ground doublet electronic PES, and so an electronic correction factor of $1 / 3$ is applied to the total rate coefficient.

For the complex $\left(\mathrm{CH}_{3} \mathrm{CH}_{2} \mathrm{O}_{2}\right)$ we have treated both the $\mathrm{OO} \ldots \mathrm{CH}_{2} \mathrm{CH}_{3}$ and the $\mathrm{CH}_{3} \ldots \mathrm{CH}_{2} \mathrm{OO}$ torsional modes as hindered rotors using a microcanonical analog of the Pitzer-Gwinn approximation. The internal rotational constants for these two hindered rotors are $2.22 \mathrm{~cm}^{-1}$ and $5.65 \mathrm{~cm}^{-1}$, respectively. Hindering potentials of period $2 \pi / 3$ are employed for both these modes, since the trans and two gauche configurations are accidentally degenerate (to within $0.1 \mathrm{kcal} / \mathrm{mole}$ ). The combination of this accidental degeneracy and the enantiomeric relation of the two gauche configurations yields an effective rotational symmetry number of 3 . The density of states of the complex $\rho_{c}(E, J)$ is calculated by convolving the exact-count harmonic contributions with both the internal and external rotations. When needed, $\rho_{c}(E)$ is calculated as $\underset{\mathrm{J}}{\mathrm{J}}(2 \mathrm{~J}+1) \rho_{\mathrm{c}}(\mathrm{E}, \mathrm{J})$. 
For the exit channel transition states (TS-2, TS-3, and TS-4) all vibrational modes are treated as harmonic oscillators, and the rotational symmetry number is unity. The sums of states $\mathrm{N}_{2}^{ \pm}(E, J)$, $\mathrm{N}_{3}{ }^{ \pm}(\mathrm{E}, \mathrm{J})$, and $\mathrm{N}_{4}^{ \pm}(\mathrm{E}, \mathrm{J})$ are computed from conventional transition-state theory by the usual methods [29]. The corresponding $N^{ \pm}(E)$ 's are calculated from $N^{ \pm}(E)=\underset{J}{\Sigma}(2 J+1) N^{ \pm}(E, J)$.

\section{RATE COEFFICIENT CALCULATIONS}

First consider the two limits, the high-pressure limit of the addition reaction and the zeropressure limit, which of course includes only the bimolecular product channel. Using $\mu$ VT-J, we can write the corresponding rate coefficient expressions as

$k_{\infty}(T)=\frac{1}{h Q_{R}(T)} \int_{0}^{\infty}\left[\sum_{J}(2 J+1) N_{1}^{ \pm}(E, J)\right] \exp (-\beta E) d E$

and $k_{0}(T)=\frac{1}{h Q_{R}(T)} \sum_{J}(2 J+1) \int_{0}^{\infty} \frac{N_{1}^{ \pm}(E, J) N_{2}^{ \pm}(E, J)}{N_{1}^{ \pm}(E, J)+N_{2}^{ \pm}(E, J)} \exp (-\beta E) d E$,

where $\beta=\left(k_{B} T\right)^{-1}, k_{B}$ is Boltzmann's constant, $h$ is Planck's constant, and $Q_{R}$ is the reactant partition function, including relative translational contributions. In these expressions the electronic degeneracies and symmetry numbers have been subsumed into $Q_{R}$ and the $N^{ \pm}(E, J)$ 's. The $\mu V T$ approximations to $k_{0}(T)$ and $k_{\infty}(T)$ are similar to the above except that there is no sum over $J$, the $N^{ \pm}$s are only functions of $\mathrm{E}$, and there is only one TS-1 for every E. Equation (4) assumes that TS-2 gives the only contribution to the bimolecular channel and that, once this TS is traversed, a complex inevitably goes on to form $\mathrm{C}_{2} \mathrm{H}_{4}+$ $\mathrm{HO}_{2}$. The latter is a safe assumption, and to check the former we have performed a few calculations with $\mathrm{N}_{2}{ }^{ \pm}(E, J)$ in Eq. (4) replaced by $\mathrm{N}_{2}{ }^{ \pm}(E, J)+N_{3}{ }^{ \pm}(E, J)+N_{4}^{ \pm}(E, J)$. This gives us an estimate of the upper limit of the error incurred by neglecting TS-3 and TS -4 as possible exit paths from the initial complex.

To calculate rate coefficients as a function of $T$ and $p$ we solve the time-dependent, onedimensional master equation. To formulate the problem, envision the situation typical in kinetics experiments,

$$
\mathrm{n}_{\mathrm{C} 2 \mathrm{H} 5} \ll \mathrm{n}_{02} \ll<\mathrm{n}_{\mathrm{He}} \text {, }
$$

where $n$ denotes number density. For the present investigation we assume that the bath gas is always helium and that the reactants are constantly maintained in a thermal distribution. Under these conditions we can write a linear master equation for $n(E)$, where $n(E) d E$ is the number density of $\mathrm{C}_{2} \mathrm{H}_{5} \mathrm{O}_{2}$ complexes between energies $\mathrm{E}$ and $\mathrm{E}+\mathrm{dE}$, and a linear rate equation for $\mathrm{n}_{\mathrm{C} 2 \mathrm{H} 5}$. Space limitations 
prevent us from giving a derivation here, but it is possible to express these equations in a simple form. After approximating the collision integral in the master equation as a sum, the problem can be posed in Dirac notation as

$$
\frac{d}{d t} \mid y(t)>=G l y(t)>\text {. }
$$

In Eq. (5), $\mid y(t)>$ is the vector of unknowns,

$$
\mid \mathrm{y}(\mathrm{t})>\quad \rightarrow \quad\left[\mathrm{y}_{1}, \ldots, \mathrm{y}_{\mathrm{i}}, . ., \mathrm{y}_{\mathrm{M}},\left(\mathrm{K}_{\mathrm{eq}} \mathrm{n}_{\mathrm{O} 2} / \Delta \mathrm{E}\right)^{1 / 2} \mathrm{x}_{\mathrm{C} 2 \mathrm{H} 5}\right]^{\mathrm{T}},
$$

where $y_{i}=y\left(E_{i}\right), E_{i}=E_{o}+(i-1) \Delta E, i=1, \ldots M, M$ is the number of grid points in the energy space, $\Delta E$ is the spacing between grid points, $\mathrm{E}_{\mathrm{o}}$ is the energy corresponding to the ground vibrational state of $\mathrm{C}_{2} \mathrm{H}_{5} \mathrm{O}_{2}, \mathrm{x}_{\mathrm{C} 2 \mathrm{H} 5}=\mathrm{n}_{\mathrm{C} 2 \mathrm{H} 5}(\mathrm{t}) / \mathrm{n}_{\mathrm{C} 2 \mathrm{H} 5}(0), \mathrm{y}(\mathrm{E})=\mathrm{x}(\mathrm{E}) / \sqrt{ } \mathrm{F}(\mathrm{E}), \mathrm{x}(\mathrm{E})=\mathrm{n}(\mathrm{E}) / \mathrm{n}_{\mathrm{C} 2 \mathrm{H} 5}(0), \mathrm{F}(\mathrm{E})$ is the equilibrium energy distribution of the $\mathrm{C}_{2} \mathrm{H}_{5} \mathrm{O}_{2}$ adduct, and $\mathrm{K}_{\text {eq }}$ is the equilibrium constant for the addition reaction, $\mathrm{C}_{2} \mathrm{H}_{5}+\mathrm{O}_{2} \leftrightarrow \mathrm{C}_{2} \mathrm{H}_{5} \mathrm{O}_{2}$. The operator $\mathrm{G}$ in our discrete energy basis is a real symmetric (Hermitian) matrix, which allows a simple solution.

We can write the solution to Eq. (5) as

$$
\operatorname{ly}(t)>=\sum_{i=1}^{M+1} e^{\lambda} t^{t} \lg i><g_{i} \mid y(0)>
$$

where the $\lambda_{i}$ and $\mid g_{i}>$ are the $M+1$ (negative) eigenvalues and eigenvectors of $G$, and $\mid y(0)>$ corresponds to $\mathrm{x}_{\mathrm{C} 2 \mathrm{H} 5}(0)=1$. Methods for diagonalizing real, symmetric matrices are highly developed, and good software is relatively easy to find. We use the DSYEV routine from LAPACK [31] to diagonalize $\mathrm{G}$.

From the solution vector $\mid y(t)>$ we get

$$
\begin{aligned}
& x_{C_{2} H_{5}}(t)=\left(K_{e q} n_{O_{2}} / \Delta E\right)^{-1 / 2} y_{M+1}(t), \\
& x_{j}(t)=\sqrt{F\left(E_{j}\right)} y_{j}(t), \quad j=1, \ldots, M
\end{aligned}
$$

$x_{\mathrm{C}_{2} \mathrm{H}_{5} \mathrm{O}_{2}}(t)=\sum_{i=1}^{M} x_{i}(t) \Delta E$

and $x_{p}(t)=1-x_{C_{2} H_{5}}(t)-x_{C_{2} H_{5} O_{2}}(t)$,

where $x_{p}=\frac{n_{C_{2} H_{4}}(t)}{n_{C_{2} H_{5}}(0)}=\frac{n_{\mathrm{HO}_{2}}(t)}{n_{C_{2} H_{5}}(0)}$.

In interpreting our results we calculate $k(T, t)$, which we define as 
$k(T, t)=-\frac{1}{n_{\mathrm{O}_{2}} x_{C_{2} H_{5}}(t)} \frac{d x_{C_{2} H_{5}}(t)}{d t}$

If all the $\mathrm{C}_{2} \mathrm{H}_{5}$ ultimately reacts (it does in the cases considered here) and we have good exponential decays, $k(T, t)=k(T)$ (the total rate coefficient) is constant in time. At sufficiently high pressure, in the temperature range roughly between $575 \mathrm{~K}$ and $700 \mathrm{~K}$, we get multiple exponential decays. In these cases we characterize the rate using Eq. (8) at the time when $\mathrm{x}_{\mathrm{C} 2 \mathrm{H} 5}=0.5$. When there is any ambiguity in the branching fraction, we define $\alpha(T, p)$, the fraction of the reaction that produces $\mathrm{C}_{2} \mathrm{H}_{4}+\mathrm{HO}_{2}$, as $\mathrm{x}_{\mathrm{p}}(\mathrm{t})$ at a time when $\mathrm{x}_{\mathrm{C} 2 \mathrm{H} 5} \approx 0.01$.

In all our master equation calculations we use a standard exponential-down model for the energy transfer function with $\left\langle\Delta \mathrm{E}_{\mathrm{d}}\right\rangle=200 \mathrm{~cm}^{-1}$. All the calculations were done with VARIFLEX.

\section{RESULTS AND DISCUSSION}

First, let's look at the behavior of the reaction from a broad perspective. Consider Figure 2, where we have plotted $k(T)$ for various pressures along with a number of experimental results $[6,8,10$, 11] at pressures ranging from slightly less than a Torr to almost an atmosphere. The upper and lower solid curves represent $k_{\infty}(T)$ and $k_{0}(T)$ respectively, calculated from $\mu$ VT-J. As expected, except for a pathological calculation at $700 \mathrm{~K}$ and $10 \mathrm{~atm}$ (where we were forced to use our somewhat arbitrary definition of $k(T, p)$ discussed above), all the rate coefficients lie between these two boundaries (within reasonable uncertainty for the experiments). From the master equation calculations it is possible to identify three different regimes of the reaction:

1) Low-temperature regime - In this regime the reaction exhibits normal behavior. The rate coefficient and branching fraction are functions of $\mathrm{T}$ and $\mathrm{p}$, and the time evolution is perfectly exponential, i.e., the rate coefficient is well defined. This regime persists up to $T \approx 600 \mathrm{~K}$.

2) Transition regime - Roughly between $600 \mathrm{~K}$ and $700 \mathrm{~K}$ the $\mathrm{x}_{\mathrm{C} 2 \mathrm{H} 5}(\mathrm{t})$ is decidedly nonexponential, at least at sufficiently high pressure. Consequently, it is impossible to extract a rate coefficient rigorously from the calculation, at least in the normal sense. The temperatures at which this occurs correspond to the equilibration of the hypothetical $\mathrm{C}_{2} \mathrm{H}_{5}+\mathrm{O}_{2} \leftrightarrow \mathrm{C}_{2} \mathrm{H}_{5} \mathrm{O}_{2}$ reaction. For the conditions of our calculations, the equilibrium fraction of $\mathrm{C}_{2} \mathrm{H}_{5}$ tied up as $\mathrm{C}_{2} \mathrm{H}_{5} \mathrm{O}_{2}$ at $500 \mathrm{~K}$ is 0.997 , but it drops off precipitously to 0.108 at $700 \mathrm{~K}$ and 0.0051 at $800 \mathrm{~K}$. The complex behavior of the reaction in this regime is due to the simultaneous dissociation of $\mathrm{C}_{2} \mathrm{H}_{5} \mathrm{O}_{2}$ to both $\mathrm{C}_{2} \mathrm{H}_{5}+\mathrm{O}_{2}$ and $\mathrm{C}_{2} \mathrm{H}_{4}+\mathrm{HO}_{2}$ after varying degrees of stabilization. Note the dramatic drop-off of the rate coefficient in Figure 2 at high pressures between $650 \mathrm{~K}$ and $700 \mathrm{~K}$ as the stabilization reaction equilibrates. Stabilization becomes problematic under these conditions, and the only outlet is the bimolecular channel. The 
temperature range for this regime is sensitive to the $\mathrm{C}_{2} \mathrm{H}_{5}-\mathrm{O}_{2}$ bond energy. We chose the value of 34 $\mathrm{kcal} / \mathrm{mole}$ used in the calculations to agree with experimental observations. It is reassuring that our G2like calculation of $33.9 \mathrm{kcal} / \mathrm{mole}$ is in excellent agreement with this number. Previous estimates [8,.30] are also compatible with these results, but the DFT bond energy of $29 \mathrm{kcal} / \mathrm{mole}$ is clearly too small.

3) High-temperature regime - The onset of this regime is at $\mathrm{T} \approx 700 \mathrm{~K}$. By $750 \mathrm{~K}$ the only products of the reaction are $\mathrm{C}_{2} \mathrm{H}_{4}+\mathrm{HO}_{2}$, and the rate-coefficient curves $\mathrm{k}(\mathrm{T}, \mathrm{p})$ in Figure 2 for all pressures have coalesced to the zero-pressure limit. This latter result is somewhat surprising, particularly when we realize that the $\mathrm{C}_{2} \mathrm{H}_{5} \mathrm{O}_{2}$ complex still suffers numerous collisions at high pressure. In this regime the reaction can be characterized by a single set of products, $\mathrm{C}_{2} \mathrm{H}_{4}+\mathrm{HO}_{2}$, and a single rate coefficient $\mathrm{k}(\mathrm{T})$ independent of pressure. As the last sentence implies, we again get good exponential decays in $\mathrm{x}_{\mathrm{C} 2 \mathrm{H} 5}(\mathrm{t})$.

Figure 3 demonstrates what we mean by normal behavior. It is a plot at $\mathrm{T}=300 \mathrm{~K}, \mathrm{p}=1$ Torr of $\mathrm{x}_{\mathrm{C} 2 \mathrm{H} 5}(\mathrm{t}), \mathrm{x}_{\mathrm{C2} 2 \mathrm{HO} 2}(\infty)-\mathrm{x}_{\mathrm{C} 2 \mathrm{H} 5 \mathrm{O} 2}(\mathrm{t})$, and $\mathrm{x}_{\mathrm{p}}(\infty)-\mathrm{x}_{\mathrm{p}}(\mathrm{t})$ on a log scale. If the reaction is governed by a single time constant (i.e. a single eigenvector of $G$ ), and we can thus identify a "good" rate coefficient, all these curves should be straight lines. They are, at least on the time scale for $\mathrm{C}_{2} \mathrm{H}_{5}$ removal.

Figure 4 is a comparison of our high-p, low-T rate coefficients with the experimental results of Kaiser and co-workers $[9,11]$. The agreement between theory and experiment is excellent. At 580 Torr, both the experimental and theoretical rate coefficients remain relatively constant from $250 \mathrm{~K}$ up to $\mathrm{T} \approx 400 \mathrm{~K}$, and then they drop off more rapidly with $\mathrm{T}$. This constancy of $\mathrm{k}(\mathrm{T}, 580 \mathrm{Torr})$ with $\mathrm{T}$, even with a weak-collider bath gas such as helium, is a strong indication that $k_{\infty}(T)$ rises with temperature, an unusual result (although not unheard of) for a barrierless reaction. Our $\mu V T-J$ prediction of $k_{\infty}(T)$ falls within the error bars of the room temperature determination of this rate coefficient reported in [9]. Wagner, et al [8] give $\mathrm{k}_{\infty}(\mathrm{T}) \approx 7 \times 10^{-12} \mathrm{~cm}^{3} / \mathrm{molec}$.-sec. almost independent of temperature, a value somewhat smaller than the experimental results and the present theoretical predictions. It is also worth noting that our $\mu \mathrm{VT}-\mathrm{J}$ and $\mu \mathrm{VT}$ predictions of $\mathrm{k}_{\infty}(\mathrm{T})$ do not differ significantly - the $\mu \mathrm{VT}$ rate coefficient is only $6 \%$ larger at $250 \mathrm{~K}$ and imperceptively larger for $\mathrm{T}>400 \mathrm{~K}$. The present prediction for $k_{\infty}(T)$ can be expressed reasonably accurately in the modified Arrhenius form,

$$
\mathrm{k}_{\infty}(\mathrm{T}) \quad=\quad 4.84 \times 10^{-13} \mathrm{~T}^{0.52} \mathrm{~cm}^{3} / \text { molec-sec., }
$$

for $250 \mathrm{~K} \leq \mathrm{T} \leq 2000 \mathrm{~K}$.

Figure 5 is a comparison of our theoretical predictions with the low pressure rate coefficients measured by Gutman and collaborators [6-8]. All their experiments were conducted at pressures ranging from slightly less than a Torr to approximately 15 Torr. Our theoretical curves corresponding to $\mathrm{p}=1$ Torr and $\mathrm{p}=20$ Torr should more or less bracket these results. Within reasonable experimental 
uncertainty, they do. The rate coefficients in the high temperature regime ( $\mathrm{T}>700 \mathrm{~K}$ ) are governed almost exclusively by TS-2, and we adjusted the value of its energy $E_{2}$ in our calculations to give good agreement with the experimental rate coefficients in this regime. This value of $E_{2}=-4.3 \mathrm{kcal} / \mathrm{mole}$ (measured from reactants) is in reasonably good agreement with our G2-like ab initio result of $\mathrm{E}_{2}=-3.0$ $\mathrm{kcal}$, but it differs somewhat from the DFT calculation of $-1.9 \mathrm{kcal} / \mathrm{mole}$. Using $\mathrm{E}_{2}=-1.9 \mathrm{kcal} / \mathrm{mole}$ in our calculations gives rate coefficients in the high temperature regime that are substantially smaller than those shown in the figure (by approximately a factor of 4 at $\mathrm{T}=1000 \mathrm{~K}$ ).

Also shown in Figure 5 are the $\mu V T$ and $\mu V T-J$ results for $k_{0}(T)$. The $\mu V T$ rate coefficient is $29 \%$ larger than that calculated from $\mu \mathrm{VT}-\mathrm{J}$ at $\mathrm{T}=250 \mathrm{~K}$, a difference that diminishes with increased temperature until it is virtually imperceptible for $\mathrm{T}>500 \mathrm{~K}$. The two rate coefficients come together at high temperature, because $\mathrm{k}_{\mathrm{o}}(\mathrm{T})$ begins to be controlled exclusively by the single tight transition state TS - 2, i.e., the flux through TS - 1 becomes effectively infinite (see Eq. (4)), and we are left with a conventional transition-state theory result, with TS -2 the transition state. The contribution to $k_{0}(T)$ from TS-3 and TS-4 is no more than $9 \%$ at $2000 \mathrm{~K}$ (calculated using the G2-like barrier heights of Table I); it is much less at lower temperatures. For $700 \mathrm{~K}<\mathrm{T}<2000 \mathrm{~K}$, we can express $\mathrm{k}_{0}(\mathrm{~T})$ as $\mathrm{k}_{0}(\mathrm{~T})=3.19$ $\times 10^{-17} \mathrm{~T}^{1.02} \exp (2035 / \mathrm{RT}) \mathrm{cm}^{3} /$ molec.-sec., which should be sufficiently accurate for flame modeling.

The transition-state energy $\mathrm{E}_{2}$ also plays a major role in determining the branching fraction $\alpha(\mathrm{T}, \mathrm{p})$ in the low-temperature regime. In Figure 6 we compare our predictions for $\alpha$ with the experimental results of Clifford, et al [12], who measured the branching fraction from room temperature to $700 \mathrm{~K}$ at a constant helium number density of $1.1 \times 10^{18} / \mathrm{cm}^{3}$. The agreement between theory and experiment is quite satisfactory. Both show a slow rise in $\alpha$ from room temperature to about $575 \mathrm{~K}$, followed by the very rapid rise between $575 \mathrm{~K}$ and $700 \mathrm{~K}$ that occurs as the $\mathrm{C}_{2} \mathrm{H}_{5}+\mathrm{O}_{2} \leftrightarrow \mathrm{C}_{2} \mathrm{H}_{5} \mathrm{O}_{2}$ reaction equilibrates.

Figure 7 shows the time history of $\mathrm{x}_{\mathrm{C} 2 \mathrm{H} 5}(\mathrm{t}), \mathrm{x}_{\mathrm{C} 2 \mathrm{H} 5 \mathrm{O} 2}(\mathrm{t})$, and $1-\mathrm{x}_{\mathrm{p}}(\mathrm{t})$ on a semi-log plot for $\mathrm{T}=$ $700 \mathrm{~K}, \mathrm{p}=100$ Torr. This plot is characteristic of the behavior we observe throughout the transition regime (at sufficiently high pressure). The reactant concentration shows a distinctly non-exponential decay. The function $\mathrm{x}_{\mathrm{C} 2 \mathrm{H} 5}(\mathrm{t})$ first decays rapidly as $\mathrm{x}_{\mathrm{C} 2 \mathrm{H} 5 \mathrm{O} 2}(\mathrm{t})$ rises. After $\mathrm{x}_{\mathrm{C} 2 \mathrm{H} 5 \mathrm{O} 2}(\mathrm{t})$ peaks, both $\mathrm{x}_{\mathrm{C} 2 \mathrm{H} 5}(\mathrm{t})$ and $\mathrm{x}_{\mathrm{C} 2 \mathrm{H} 5 \mathrm{O} 2}(\mathrm{t})$ decay with the same exponential time constant. The most interesting result from Figure 7 is that the bimolecular products, $x_{p}(t)$, are governed by this same long-term time constant even at very short times. The calculations indicate that an experiment that measured only the products would be able to detect the transition regime only through the rapid rise in $\alpha(T, p)$ with $T$ at these temperatures. There would be no indication of any difficulty in determining a good rate coefficient from such experimental data in this regime. 
It is instructive to interpret our results in terms of the eigenvalues and eigenvectors of $\mathrm{G}$. Two eigenvalues play a major role. At low temperature it is the second largest eigenvalue of $\mathrm{G}$ (i.e. the second least negative), $\lambda_{2}$, that determines the time evolution of both the reactants and products. The largest eigenvalue, $\lambda_{1}$, is associated with the thermal dissociation of $\mathrm{C}_{2} \mathrm{H}_{5} \mathrm{O}_{2}$ to $\mathrm{C}_{2} \mathrm{H}_{4}+\mathrm{HO}_{2}$ and is much larger than $\lambda_{2}$. This largest eigenvalue decreases rapidly with increasing temperature, and in the transition regime $\lambda_{1}$ and $\lambda_{2}$ are of comparable size. We thus observe the behavior described above. In the high-temperature regime there is again a separation of the eigenvalues, but now it is $\lambda_{1}$ that governs the time evolution of $\mathrm{C}_{2} \mathrm{H}_{5}$ and $\mathrm{O}_{2}$ to $\mathrm{C}_{2} \mathrm{H}_{4}+\mathrm{HO}_{2}$.

A question about the importance of the direct abstraction channel always arises in discussions of alkyl radical $+\mathrm{O}_{2}$ reactions. For the present case we have used the G2-like transition state of Table I to calculate a direct abstraction rate coefficient,

$$
\mathrm{k}_{\mathrm{a}}(\mathrm{T})=1.93 \times 10^{-17} \mathrm{~T}^{1.57} \exp (-20578 / \mathrm{RT}),
$$

for $1000 \mathrm{~K} \leq \mathrm{T} \leq 2000 \mathrm{~K}$. This rate coefficient is about a factor of 10 smaller at $2000 \mathrm{~K}$ than the $\mathrm{k}(\mathrm{T})$ discussed above. The difference is even greater at lower temperatures, and thus it is probably reasonable to neglect $\mathrm{k}_{\mathrm{a}}(\mathrm{T})$ in most applications.

\section{CONCLUDING REMARKS}

We have used a variety of theoretical techniques to study the reaction between ethyl and $\mathrm{O}_{2}$ over very wide ranges of temperature and pressure. These include electronic-structure theory, variational transition-state theory, and solutions to the time-dependent master equation. Our predictions of rate coefficients and product distributions are in very good agreement with experiment. Moreover, the values of the $\mathrm{C}_{2} \mathrm{H}_{5}-\mathrm{O}_{2}$ bond energy and the exit-channel transition-state energy of $34 \mathrm{kcal} / \mathrm{mole}$ and $-4.3 \mathrm{kcal} / \mathrm{mole}$ (measured from reactants), respectively, deduced from the master equation results compare favorably with the $33.9 \mathrm{kcal} / \mathrm{mole}$ and $-3.0 \mathrm{kcal} / \mathrm{mole}$ calculated from our G2-like method.

The most interesting aspect of our analysis is the prediction of three different regimes of the reaction, discussed extensively in the text. For temperatures larger than $\mathrm{T} \approx 700 \mathrm{~K}$, the reaction can be written as a simple elementary step,

$$
\mathrm{C}_{2} \mathrm{H}_{5}+\mathrm{O}_{2} \leftrightarrow \mathrm{C}_{2} \mathrm{H}_{4}+\mathrm{HO}_{2},
$$

with a rate coefficient $\mathrm{k}(\mathrm{T})$ independent of pressure, even though the reaction goes through an intermediate complex that may suffer numerous collisions. Moreover, the rate coefficient is the same as that at the zero-pressure (collisionless) limit. In modified Arrhenius form, we can write $k(T)$ in this regime as

$$
\mathrm{k}(\mathrm{T})=3.19 \times 10^{-17} \mathrm{~T}^{1.02} \exp (2035 / \mathrm{RT}) \mathrm{cm}^{3} / \text { molec.-sec. }
$$




\section{ACKNOWLEDGEMENT}

We would like to thank Dr. Eileen Clifford for making her experimental results available to us prior to publication. This work was supported by the United States Department of Energy, Office of Basic Energy Sciences, Division of Chemical Sciences.

\section{REFERENCES}

1. Knox, J. H., Combust. Flame 9:297 (1965)

2. Benson, S. W., J. Am. Chem. Soc. 87:972 (1965)

3. Benson, S. W., Prog. Energy Combust. Sci. 7:125-134 (1981)

4. Plumb, I. C., Ryan, K. R., Int. J. Chem. Kinet. 13:1011 (1981)

5. McAdam, K. G., Walker, R. W., J. Chem. Soc., Faraday Trans. 2 83:1509 (1987)

6. Slagle, I. R., Feng, Q., Gutman, D., J. Phys. Chem. 88:3648 (1984)

7. Slagle, I. R., Ratajczak, E., Gutman, D., J. Phys. Chem 90:402 (1986)

8. Wagner, A. F., Slagle, I. R., Sarzynski, D., Gutman, D. J., Phys. Chem. 94:1853 (1990)

9. Kaiser, E. W., Wallington, T. J., Andino, J. M., Chem. Phys. Lett. 186:309 (1990)

10. Kaiser, E. W., Lorkovic, I. M., Wallington, T. J., J. Phys. Chem 94:3352 (1990)

11. Kaiser, E. W., J. Phys. Chem. 99:707-711 (1995)

12. Clifford, E., Farrell, J., DeSain, J., and Taatjes, C., "Production of $\mathrm{HO}_{2}$ from Ethyl Radical $+\mathrm{O}_{2}$ Measured from 298-700 K," poster presented at the Twenty-Fifth International Symposium on Free Radicals, Flagstaff, AZ, August 15-20 (1999)

13. Verkatesh, P. K., Dean, A. M., Cohen, M. H., and Carr, R. W., J. Chem. Phys. 111:8313-8329 (1999)

14. Bozzelli, J. W., Dean, A. M., J. Phys. Chem. 94:3313 (1990)

15. Green, W. H., Int. J. Chem. Kinet. 52:837 (1994)

16. Ignatev, I. S., Xie, Y., Allen, W. D., and Schaefer, H. F., J. Chem. Phys. 107:141 (1997)

17. Shen, D. L., Moise, A., and Pritchard, H. O., J. Chem. Soc. Farad. Trans. 91:1425 (1995)

18. Becke, A. D., J. Chem. Phys. 98:5648 (1993)

19. Curtiss, L. A., Raghavachari, R., Trucks, G. W., and Pople, J. A., J. Chem. Phys. $94: 7221$ (1991)

20. Curtiss, L. A., Raghavachari, R., and Pople, J. A., J Chem. Phys. 98:1293 (1993)

21. Bauschlicher, C. W., and Partridge, H., J. Chem Phys. 103:1788 (1995)

22. Miller, J. A. and Klippenstein, S. J., "Theoretical Considerations in the $\mathrm{NH}_{2}+\mathrm{NO}$ Reaction," $J$. Phys. Chem. A, in press (1999)

23. Varshni, V. P., Rev. Mod. Phys. 29:664-682 (1957)

24. Klippenstein, S. J., Wagner, A. F., Dunbar, R. C., Wardlaw, D. M., Robertson, S. H. Variflex Version $1.07 \mathrm{~m}$ (Nov. 11, 1999)

25. Klippenstein, S. J., J. Phys. Chem 98:11459-11464 and references cited therein (1994)

26. Pitzer, K. S., and Gwinn, W. D., J. Chem. Phys. 10:428 (1942)

27. Curtiss, L. A. Rachavachari, R., Redfern, P. C., Rassolov, V., and Pople, J. A., J. Chem. Phys. 98:1293: (1993)

28. Pitzer, K. S., J. Chem. Phys. 14:239 (1946)

29. Miller, J. A., Parrish, C., Brown, N. J., J. Phys. Chem 90:3339 (1986)

30. Knyazev, V. D., and Slagle, I. R., J. Phys. Chem. A, 102:1770 (1998) 
31. Anderson, E., Bai, Z., Bishof, C., Demmel, J., Dongarra, J., DuCroz, J., Greenbaum, A., Hammerling, S., McKenney, A., Ostronchov, S., and Sorensen, D., "LAPACK Users' Guide, SIAM, Philadelphia, PA, 1992

\section{FIGURE CAPTIONS}

1. Reaction coordinate diagram for the $\mathrm{C}_{2} \mathrm{H}_{5}+\mathrm{O}_{2}$ reaction, based primarily on the $\mathrm{G} 2$-like energies of Table I.

2. Isobaric rate coefficients as a function of temperature

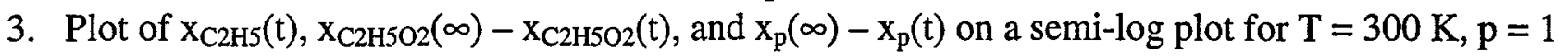
Torr. Straight lines indicate "normal" behavior.

4. Comparison of high-pressure rate coefficients with experiment.

5: Comparison of low-pressure rate coefficients with experiment.

6. Comparison of the branching fraction $\alpha(T)$ with the experiments of Clifford, et al. [12] for a fixed helium number density of $1.1 \times 10^{18} / \mathrm{cm}^{3}$.

7. Time history of $\mathrm{x}_{\mathrm{C} 2 \mathrm{H} 5}(\mathrm{t}), \mathrm{x}_{\mathrm{C} 2 \mathrm{HSO} 2}(\mathrm{t})$, and $1-\mathrm{x}_{\mathrm{p}}(\mathrm{t})$ for $\mathrm{T}=700 \mathrm{~K}, \mathrm{p}=100$ Torr. 
TABLE I

Energetics Relative to Reactants for the Stationary Points in the $\mathrm{C}_{2} \mathrm{H}_{5}+\mathrm{O}_{2}$ Reaction.

Energies in $\mathrm{kcal} / \mathrm{mole}$

\begin{tabular}{|c|c|c|c|c|}
\hline Species & $\overline{\text { B3LYP }}$ & G2'-like & $\left\langle\mathbf{S}^{2}\right\rangle^{d}$ & $\overline{\exp { }^{(e)}}$ \\
\hline$\overline{\mathrm{C}_{2} \mathrm{H}_{5} \mathrm{O}_{2}(\mathrm{~g})}$ & $-29.0^{\mathrm{a}}$ & -33.9 & 0.763 & -34.0 \\
\hline $\mathrm{C}_{2} \mathrm{H}_{5} \mathrm{O}_{2}(\mathrm{t})$ & $-29.0^{\mathrm{a}}$ & -33.8 & 0.763 & -34.0 \\
\hline TS-2 & $-1.9^{\mathrm{a}}$ & -3.0 & 0.855 & -4.3 \\
\hline TS-3 & $8.0^{\mathrm{a}}$ & 3.1 & 0.813 & \\
\hline $\mathrm{CH}_{2} \mathrm{CH}_{2} \mathrm{OOH}$ & $-9.9^{\mathrm{a}}$ & -17.0 & 0.763 & \\
\hline TS-5 & $1.5^{\mathrm{a}}$ & 1.9 & 1.023 & \\
\hline $\mathrm{CH}_{2} \mathrm{CH}_{2} \cdots \mathrm{HOO}$ & $-14.0^{\mathrm{a}}$ & -16.6 & 0.762 & \\
\hline $\mathrm{C}_{2} \mathrm{H}_{4}+\mathrm{HO}_{2}$ & $-11.2^{\mathrm{a}}$ & -12.7 & 0.763 & \\
\hline TS-6 & $1.5^{b}$ & -0.6 & 1.297 & \\
\hline $\mathrm{C}_{2} \mathrm{H}_{4} \mathrm{O}+\mathrm{OH}$ & $-25.2^{b}$ & -34.0 & 0.757 & \\
\hline TS-4 & $14.8^{\mathrm{b}}$ & 8.2 & 0.950 & \\
\hline $\mathrm{CH}_{3} \mathrm{CHO}+\mathrm{OH}$ & $-56.5^{b}$ & -61.3 & 0.757 & \\
\hline Abstraction & $9.5^{6}$ & 18.2 & 1.687 & \\
\hline
\end{tabular}
a. From Ref. 2, using the TZ2Pf basis function
b. Present work employing the $6-311++G(d, p)$ basis set
c. Approximate E[(QCISD(T)/6-311++G(3df,2pd)] energy as described in Eq. (1)
d. Average spin squared for the MP2 component of the G2-like calculations
e. Deduced from comparing predicted kinetic behavior with experiment 


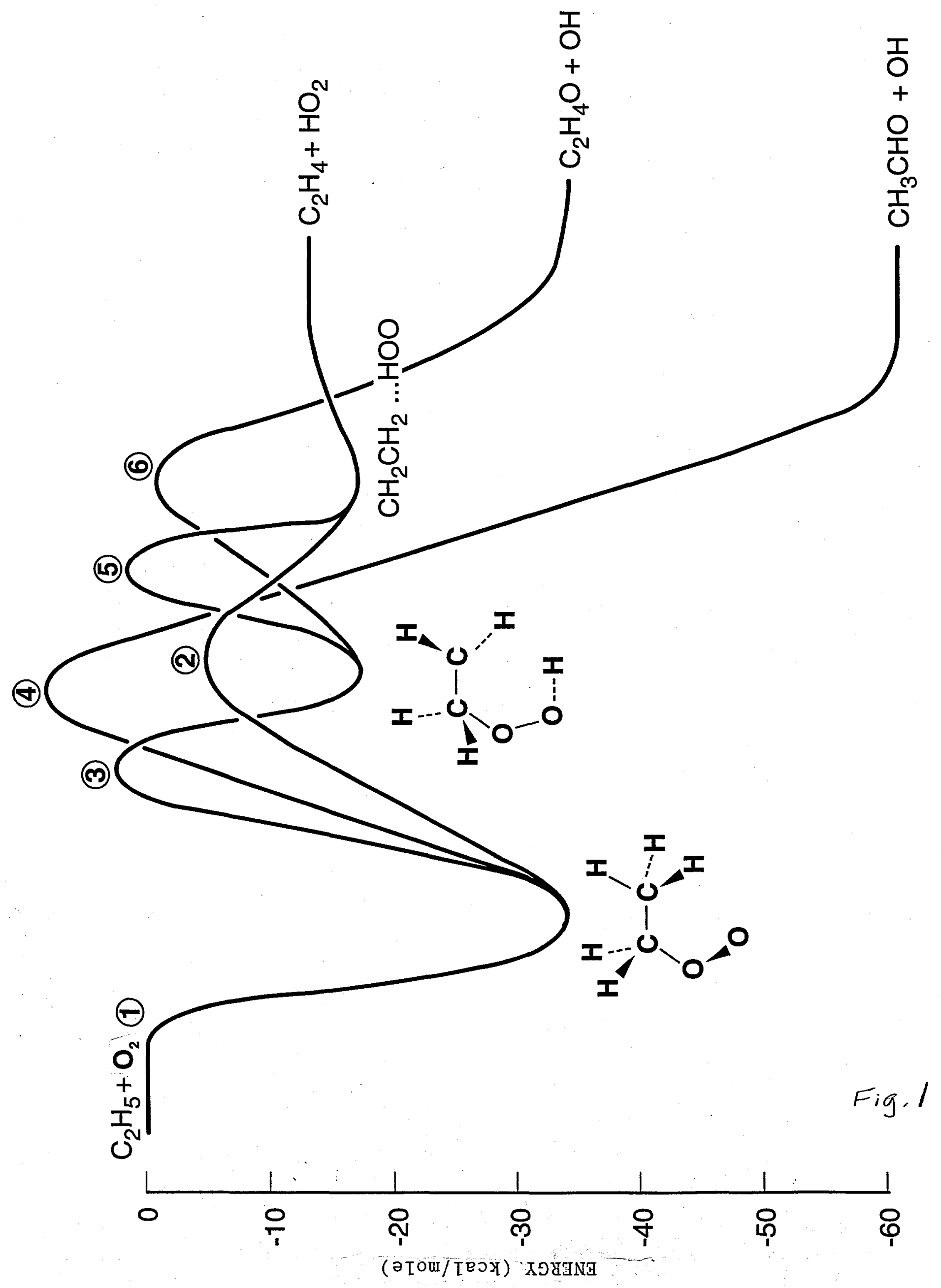




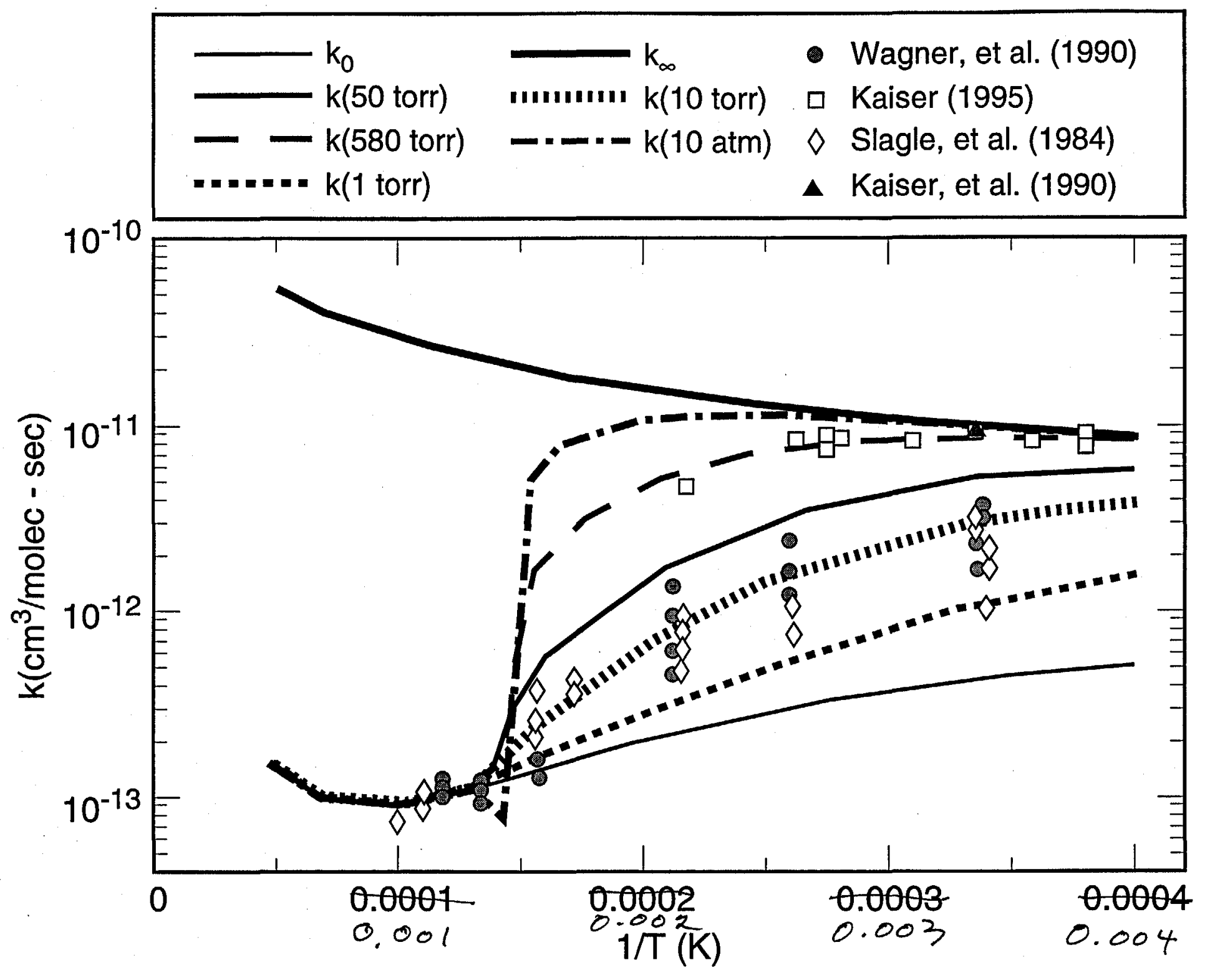




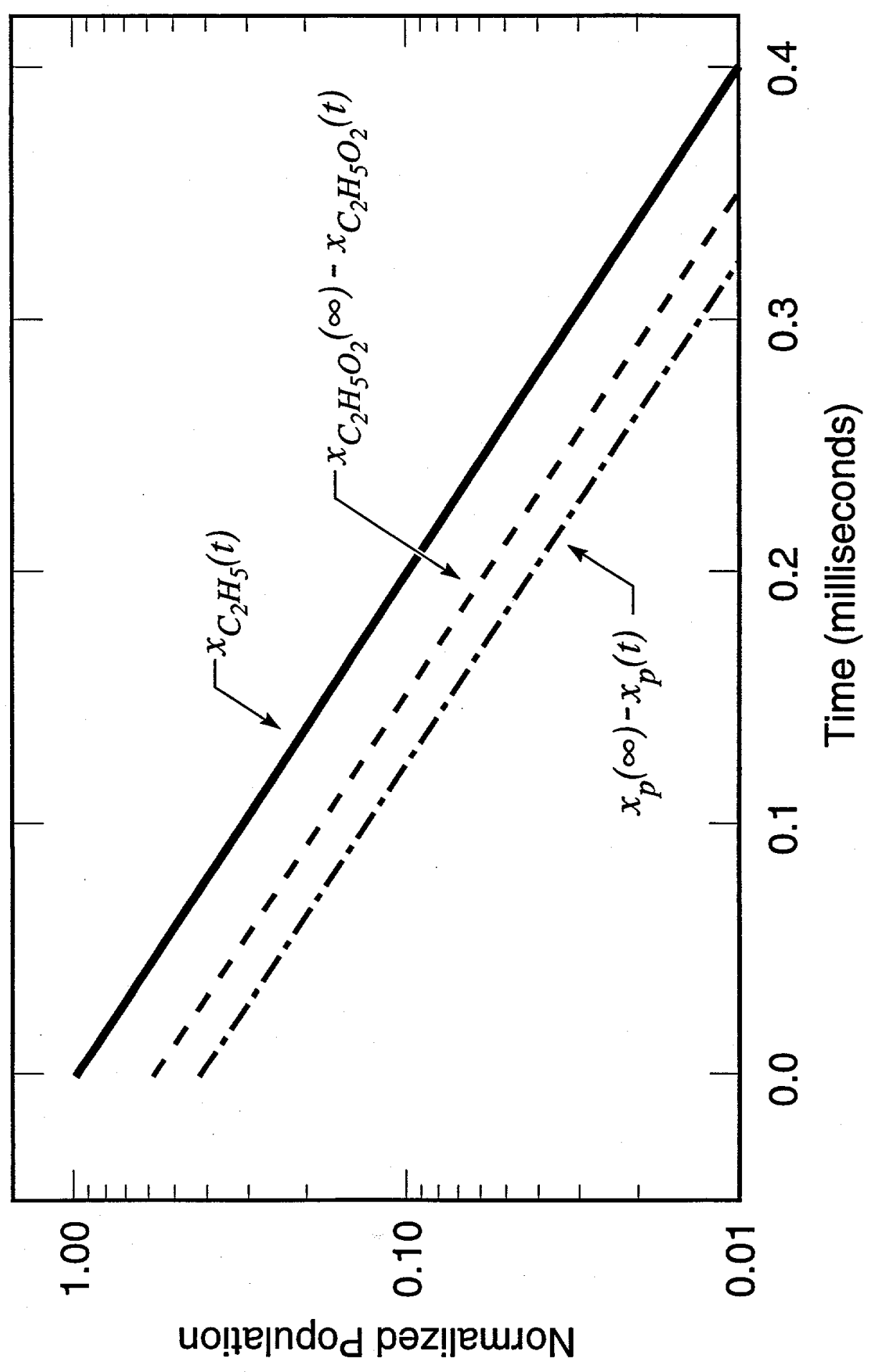

Fig. 3 


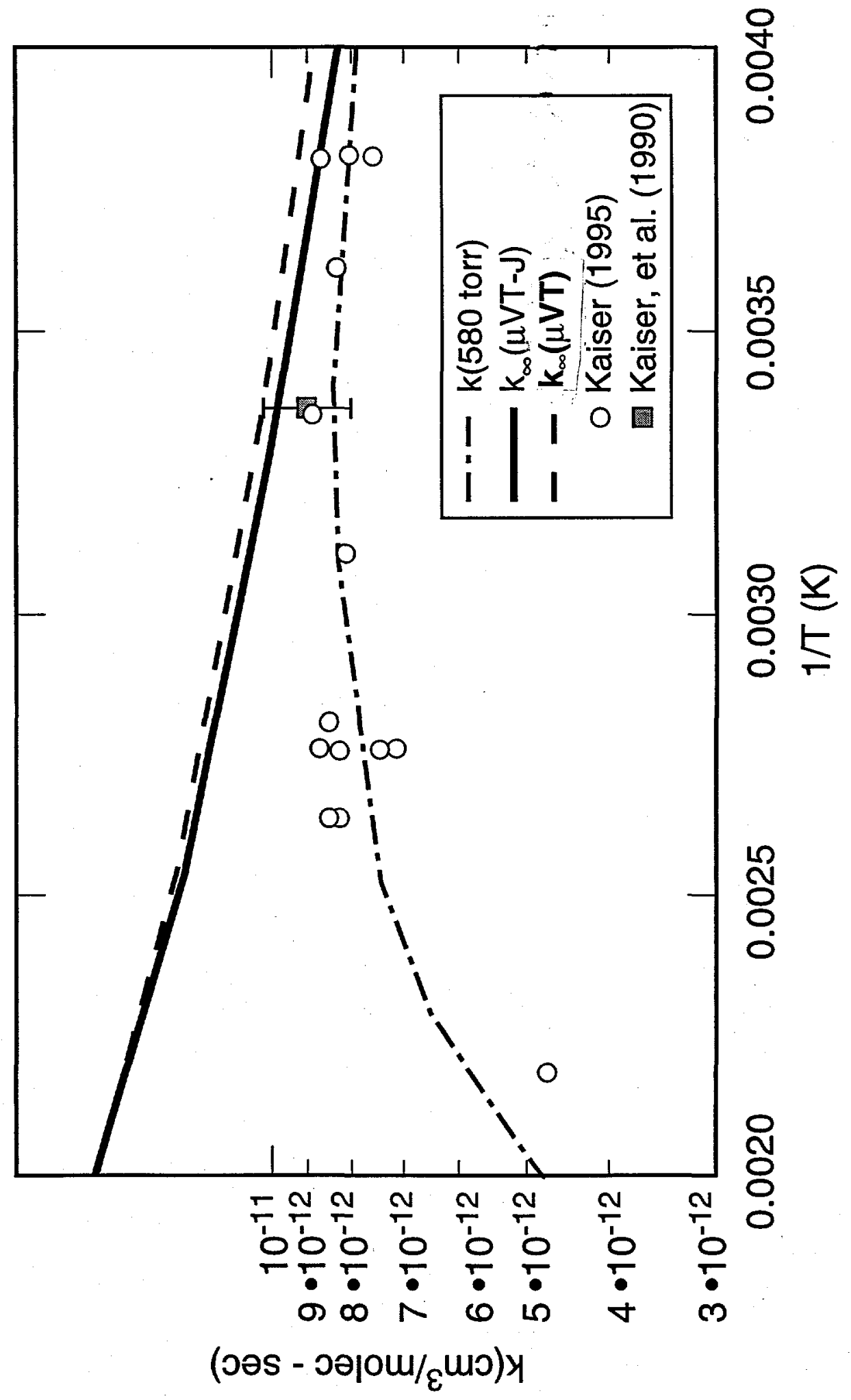

Fig. 4 


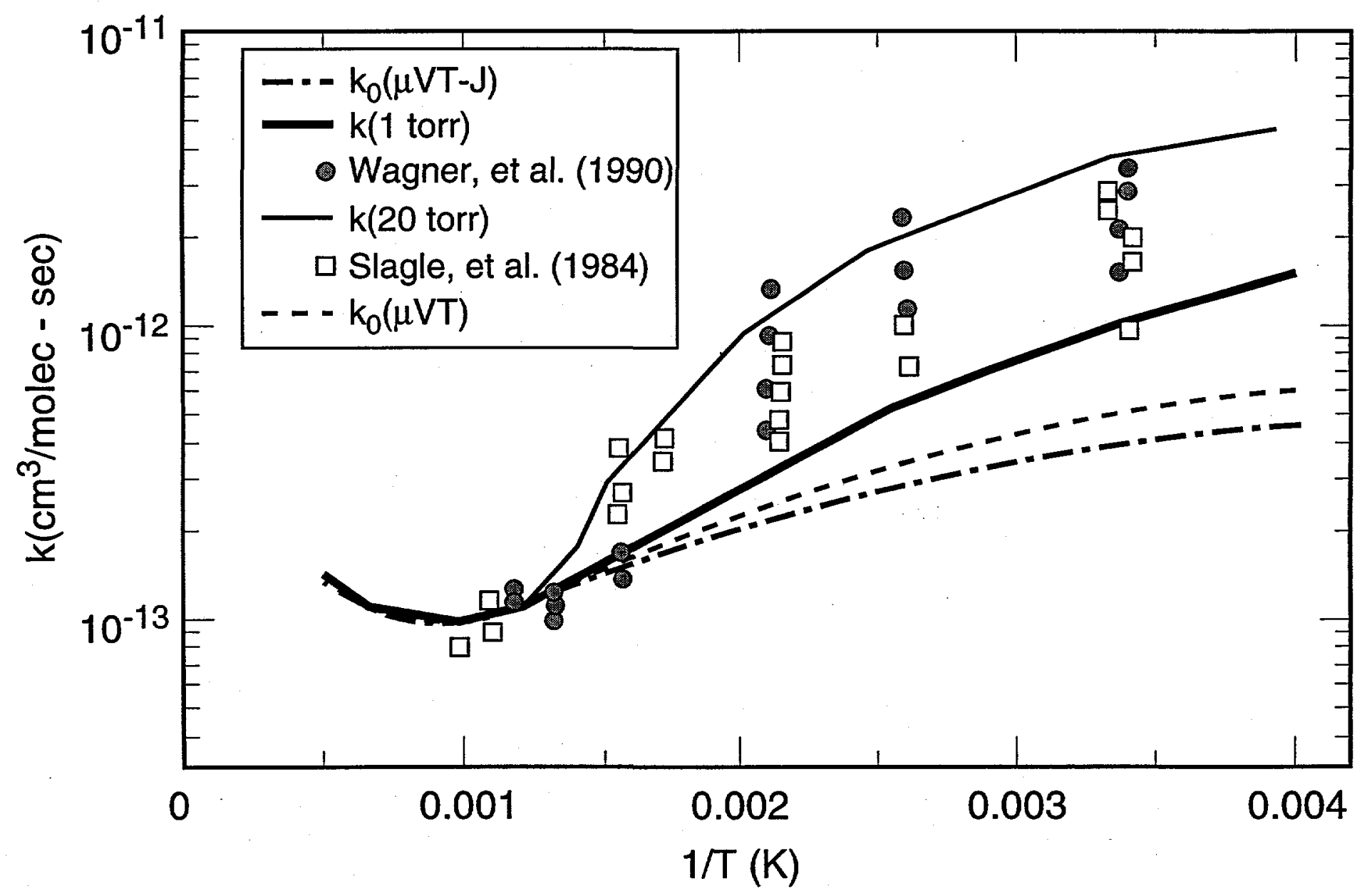

Fig.5 


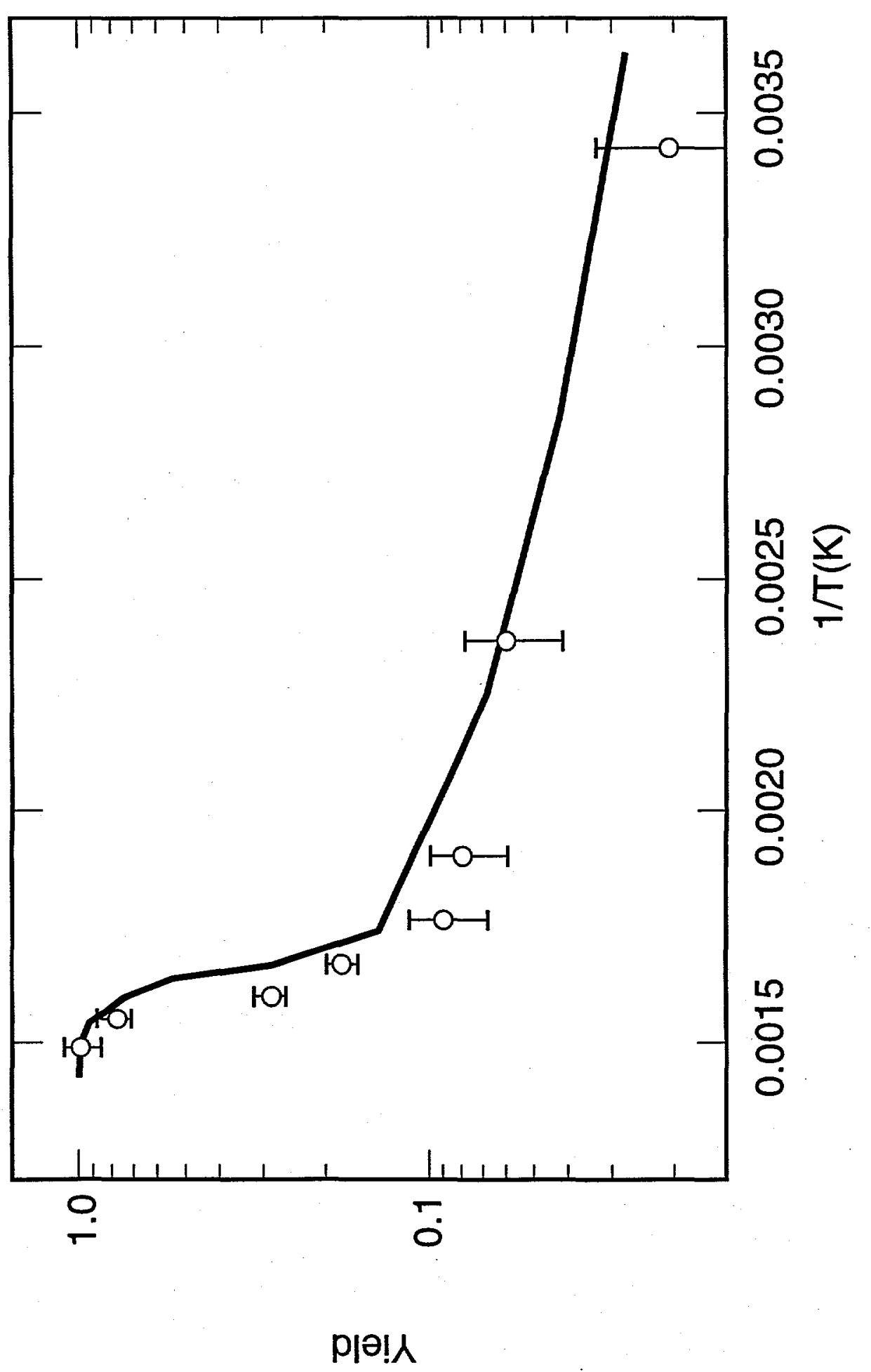

Fig. 6 


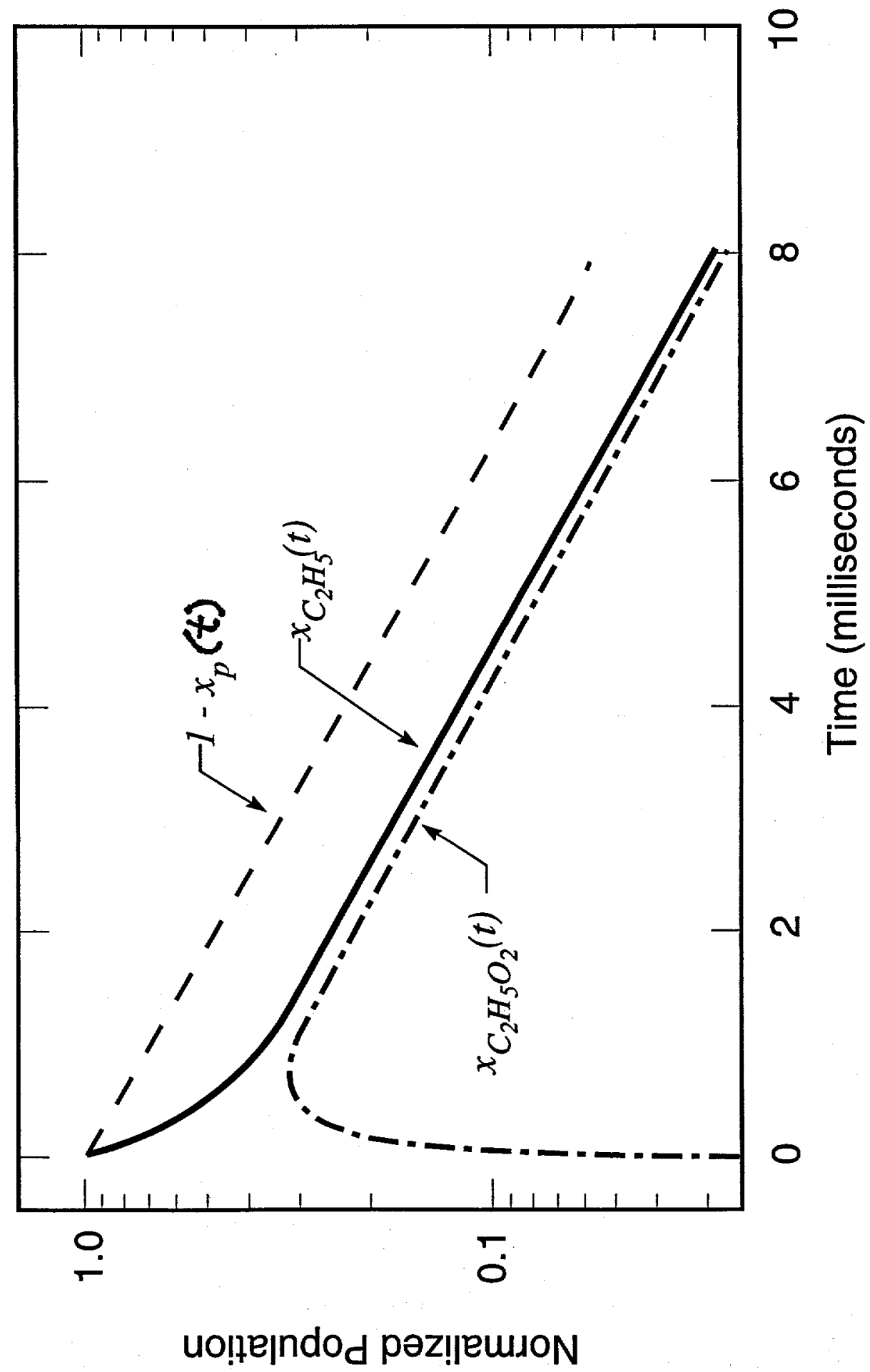

Fig. 7 